\title{
ESTUDIOS
}

\section{La titulización de la ayuda al desarrollo (International Finance Facility)}

\section{Manfred Nolte '}

Palabras clave: International Finance Facility (IFF), financiación del desarrollo, Objetivos de desarrollo del Milenio (ODM).

Key words: International Finance Facility (IFF), development financing, Millennium Development Goals (MDG).

El presente trabajo aborda el análisis y posicionamiento frente a una reciente propuesta de financiación del desarrollo: la International Finance Facility (en adelante IFF).

Comenzamos presentado el origen de la propuesta. A continuación se explica con algún detalle cuáles son las características de este mecanismo de financiación del desarrollo. En los dos apartados siguientes proponemos algunas valoraciones sobre la viabilidad técnica y política (a partir de una experiencia piloto) de este nuevo instrumento de desarrollo.

Siendo la titulización una técnica de amplio uso en los mercados financieros nuestro foco de atención se sitúa en verificar que la IFF adopta los estándares de dicha figura y es así correctamente interpretada por el mercado. El apartado 5 analizará las ventajas e inconvenientes, las luces y las sombras de este instrumento de cara al desarrollo. Terminaremos con unas breves conclusiones.

\section{Origen de la propuesta}

Al igual que en otros nuevos instrumentos de financiación del desarrollo, el origen de la idea se sitúa en el altísimo riesgo existente de que al término del periodo proyectado (2015) no se alcancen los compromisos adquiridos en 2000 en relación a los Objetivos de Desarrollo del

${ }^{1}$ Colaborador de ALBOAN. 
Milenio $(\mathrm{ODM})^{2}$. Aun cuando es amplio el abanico de factores que contribuyen a este fracaso, la ausencia de recursos es uno de los más cruciales. Dicho riesgo ha quedado plasmado en informes de seguimiento de la máxima credibilidad ${ }^{3}$. En el plano financiero, la Comisión Zedillo en 2002 (Monterrey) advirtió que la ayuda al desarrollo debía duplicarse, volcando 50 mil millones de dólares adicionales al año en los países pobres hasta el 2015. Según el Informe Sachs ${ }^{4}$ la Ayuda Oficial al Desarrollo (AOD) debería incrementarse en 73 mil millones de dólares en 2006 llegando a 135 mil millones en 2015 si se aspira a que todos los países alcancen los ODM. ¿ंCómo cebar la bomba para activar fondos, que en el plano teórico están universalmente asumidos, pero que en la práctica se encuentran estancados? Gordon Brown y su equipo responden imaginativamente y presentan a la comunidad de países desarrollados la llamada IFF, como propuesta del Gobierno británico.

La propuesta originaria data de $2003^{5}$. Fue sustituida en 2004 por otra de trazos más sistemáticos y que constituye el soporte básico para interpretar a los autores del Proyecto. Denominaremos a esta última fuente Documento Base/IFF (DB/IFF) ${ }^{6}$.

\section{Características del Mecanismo}

La IFF recurre a una práctica ampliamente difundida en los mercados financieros internacionales: la titulización. La titulización no es otra cosa que la transformación de unos activos reflejados en el balance de una entidad, o bien de derechos futuros, en valores de renta fija susceptibles de ser colocados en el mercado a los inversionistas que los demanden. Estos títulos producen liquidez para su cedente mediante un vehículo especial -"Vehículo de objetivo especial"- conocido como "fondo de titulización". Una vez escogido un instrumento de probada efectividad, profundidad y liquidez en los mercados internacionales procedía la definición de roles. La IFF, al mismo tiempo una línea de crédito y un vehículo especial, va a ser la encargada de titulizar unos activos de naturaleza peculiar.

Se trata de activos que garantizan los bonos a largo plazo emitidos por el Fondo especial IFF, por cuenta y destino de los países pobres, con el aval explícito de los países donantes. El aval se refiere a los flujos de ayuda que, a partir de 2015, tengan comprometidos los países ricos en concepto de Ayuda Oficial al Desarrollo (AOD).

\footnotetext{
${ }^{2}$ Establecidos en 2000 en la Asamblea General de Naciones Unidas. Cfr. www.developmentgoals/com, www.unmilleniumproject.org/goals/index.htm.

3 J. SACHS (2005a). También WORLD ECONOMIC FORUM (2005).

${ }^{4}$ J. SACHS (2005a), Op.cit.

${ }^{5}$ H. M. Treasury (2003); H. M. Treasury (2004).

${ }^{6}$ H. M. TReAsury (2004).
} 
Contemplamos ${ }^{7}$ un mecanismo financiero temporal para contribuir a la obtención de los 50 mil millones de dólares anuales requeridos en forma de AOD adicional hasta el 2015. La IFF estaría obteniendo y distribuyendo fondos para el desarrollo, durante aproximadamente 15 años. El período de amortizaciones se extendería durante otros 15 años más hasta el vencimiento de la última emisión parcial del programa que tendría lugar en 2015, prolongándose en consecuencia hasta el 2030, momento en que se producirá la extinción del programa y la disolución del vehículo.

Es un instrumento de carga frontal9 de la ayuda de los países donantes. La acepción de "carga frontal" implica en sí misma que la IFF no crea nuevos recursos, o recursos adicionales. Simplemente los adelanta. Basado en compromisos a largo plazo de los países donantes, la IFF apalancaría capitales en los mercados internacionales mediante la emisión de bonos. La IFF, financiada por los países donantes, sería la responsable de la redención de los bonos a los titulares inversores finales, incluido el servicio de la deuda, comisiones frontales, gastos de gestión y mantenimiento de las emisiones del llamado "vehículo emisor"10.

Los países donantes podrán acordar un conjunto de "principios de alto nivel" a la hora de asignar y desembolsar la ayuda que incrementará aún más la efectividad de la misma. Entre ellos pueden citarse los siguientes ${ }^{11}$ :

- La ayuda derivada de la IFF debería ser utilizada para financiar inversiones clave que ayuden a los países a situarse en una senda sostenible y duradera de reducción de la pobreza, de prosperidad y de participación en la economía mundial.

- Se trataría de recursos no vinculados a contratos con proveedores del país donante. Según $\mathrm{DB} / \mathrm{IFF}^{22}$ alrededor del $21 \%$ del total de la AOD está vinculada. Sólo 4 de los 22 países del Comité de Ayuda de la OCDE (CAD) tenían su ayuda desligada de proveedores en 2001.

- Recursos asignados a programas predictibles de duración mínima de tres años. Si los gobiernos tienen que adoptar compromisos a largo plazo para invertir en sistemas e infraestructuras y atajar así las causas antes que los síntomas de la pobreza, los programas de ayuda tienen que extenderse al medio plazo. Los flujos de ayuda inpredictibles provocan una gestión económica errática, añadiendo una incertidumbre considerable a unas economías ya de por

\footnotetext{
7 DB/IFF, p. 13.

${ }^{8} \mathrm{DB} / \mathrm{IFF}$, p. 24.

9 "Carga frontal", o front loading, es la activación al día de hoy de unos flujos futuros mediante la titulización.
} ${ }^{10}$ Aun cuando el DB/IFF, pp. 13,3.4, establece que se trata de un mecanismo de préstamo de tradición bien establecida,
incluso entre los países donantes y el propio Banco Mundial, la observación debe ser matizada, ya que, en la IFF, por
tratarse de un mecanismo de titulización, los países pobres no se endeudan ni toman cantidad alguna a préstamo en
sentido estricto, sino que movilizan o anticipan derechos de crédito legalmente reconocidos vendiéndolos, sin proceso
de restitución.

${ }^{11} \mathrm{DB} / \mathrm{IFF}$ p. 17, 4.1.

${ }^{12}$ DB/IFF p.14, 3.9 
sí sujetas a shocks estacionales. Los recursos se desembolsarán bajo la forma de donaciones y estarán dirigidos a un amplio abanico de receptores.

- Recursos orientados a países muy pobres. Aún es excesiva la ayuda relativa dirigida a países con niveles de renta relativamente alta.

El Gráfico 1 reproduce sucintamente la estructura de la IFF tal y como se muestra en DB/IFF ${ }^{13}$. En él se recoge el compromiso de una serie de pagos anuales por parte de los países desarrollados. Estos pagos garantizarían los programas durante 15 años de la IFF. El Gráfico 2 ilustra acerca de un hipotético programa de 50 mil millones de dólares al año desde 2010, asumiendo el servicio de la deuda con flujos nominales constantes. A partir de 2018 parte de la asignación corriente en $A O D$ se aplica a la amortización de emisiones vivas IFF, por lo que la ayuda decrece.

\section{Gráfico I:Visión general de la IFF}

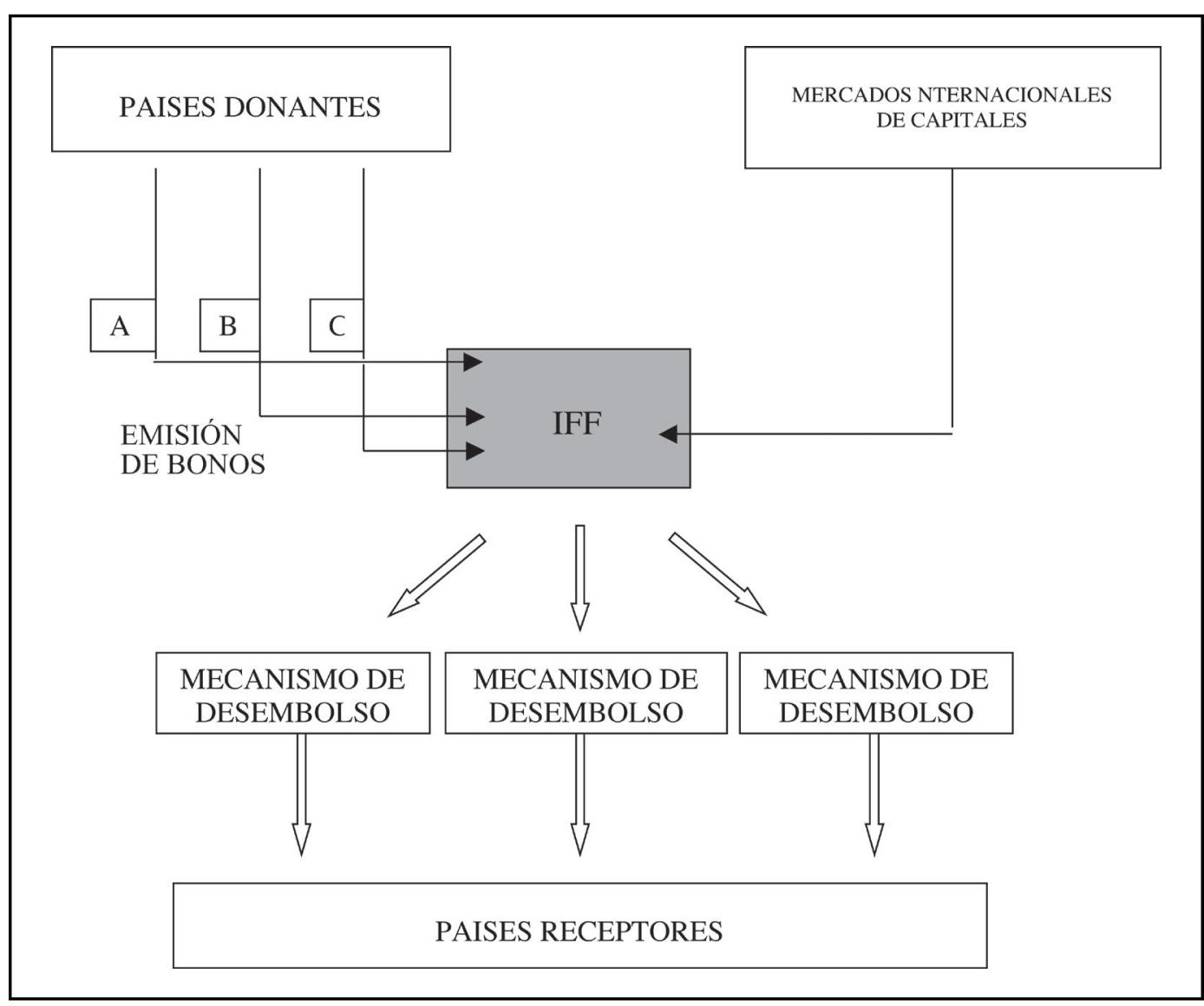

Fuente: Tesoro británico.

${ }^{13} \mathrm{DB} / \mathrm{IFF}$, p. 17,4.1. 
Gráfico 2:Activación de la IFF y total de AOD resultante

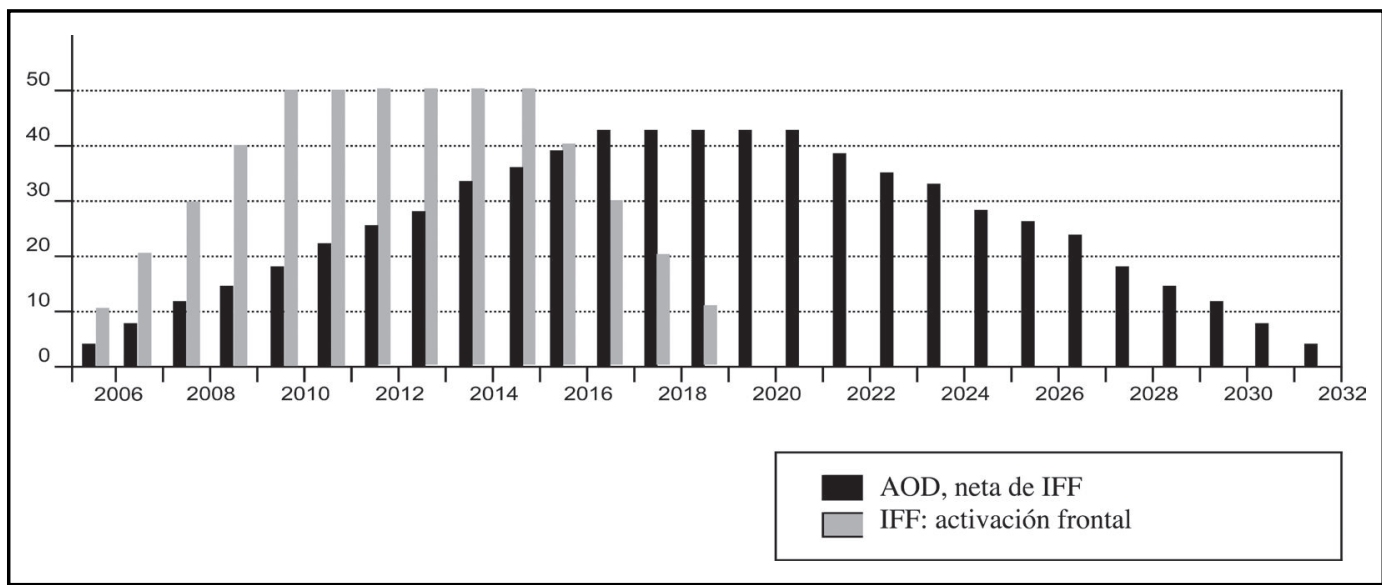

Fuente: Tesoro británico.

Especial relevancia revisten algunas características adicionales:

- Las garantías de los países donantes serían legalmente vinculantes, aunque sujetas a una "condición financiera de rango prioritario"14. Esta condición establece que las garantías de los países donantes estarán en cualquier caso sujeto a que los países receptores cumplan con la "condición básica del buen gobierno". Cualquier quiebra de dicho principio facultaría al país donante a suspender los pagos anuales comprometidos para la IFF en relación con tal receptor. Como criterio básico de buen gobierno se señala que el país receptor en cuestión no se encuentre en mora prolongada de sus obligaciones crediticias con el FMI.

- En general los países donantes serían responsables mancomunados no solidarios de los pagos a la IFF. Un país donante que participa en la IFF no se responsabiliza de los riesgos fallidos de otro país donante. En todo caso, es previsible que el aval incondicional agregado a las emisiones por los países ricos otorgue a los bonos la máxima calificación crediticia (rating soberano) con el consiguiente ahorro de los costes de financiación.

- La IFF canalizaría sus fondos a través de los mecanismos bilaterales o multilaterales ya existentes. La mecánica detallada ${ }^{15}$ de las decisiones de desembolso y asignación de los recursos de la IFF dependerá obviamente de la estructura de gobierno de la IFF. Tanto esta estructura como los principios básicos de asignación de fondos serían negociados y fijados por los países donantes en el momento de la constitución de la IFF.

\footnotetext{
${ }^{14}$ Tal condición, "high-level financing condition", es un pacto (covenanA) del contrato de garantía de los bonos y, como se señalará mas adelante, es uno de los puntos mas vulnerables de la IFF.
}

${ }^{15} \mathrm{DB} / \mathrm{IFF}$, p. $18,4.10$. 
Según se lee en el DB/IFF, desde su publicación, la IFF ha recibido un amplio apoyo de los mercados emergentes, países en vías de desarrollo e instituciones internacionales, comunidades de fe, ONG así como del mundo de la empresa privada.

En cuanto que la AOD responde a un imperativo moral, socialmente debido, y políticamente endosado en repetidas proclamaciones públicas, podemos sostener legítimamente que se trata de la titulización de una moratoria en la que incurren los países del Norte en relación con los países del Sur. Por citar la ayuda del CAD (Comité de Ayuda al Desarrollo) de la OCDE, su contribución en AOD en 2006 alcanzó la suma de 103,9 mil millones de dólares, el 0,3\% de su PIB, muy distantes de los 242 mil millones de dólares que se hubiesen destinado de haberse aportado el $0,7 \%$ de sus PIB. No nos parece aventurado cifrar en la diferencia de ambas sumas, 138 mil millones de dólares, el importe de la moratoria anual al desarrollo de los países ricos, y que debiera ser "restituida" y no solamente adelantada.

\section{Viabilidad técnica: el proceso de titulización de activos}

Como ya hemos indicado, la titulización puede definirse ${ }^{16}$ como la transformación de unos activos reflejados en el balance de un banco, una institución pública o una empresa privada, en unos valores generalmente de renta fija susceptibles de ser colocados en el mercado a unos inversionistas demandantes de dichos títulos. Estos títulos producen liquidez para su cedente mediante un vehículo especial -Vehículo de objetivo especial o Special Purpose Vehicle-VOE/ $S P V$, conocido como Fondo de Titulización ${ }^{17}$. Los flujos de caja obtenidos por el fondo se mantienen al margen de procedimientos concursales de la entidad cedente ya que el fondo tiene personalidad jurídica independiente.

La propuesta de Gordon Brown no establece en su publicación oficial (DB/IFF) de forma explícita que la IFF sea un vehículo de objetivo especial -SPV-, ni que el proceso de anticipo de fondos que describe sea el de un mecanismo de titulización ${ }^{18}$. Sin embargo, la movilización en forma de bonos de compromisos presupuestarios de ayuda futura contraídos por los países desarrollados con los países pobres- a su vez derechos de crédito de estos últimos-y su venta a inversores

\footnotetext{
${ }^{16}$ Existen tres tipos principales de titulización: a) de venta real; b) sintética; c) de negocio global. En la primera (true sale securitization), la entidad vende activos a un VPE/SPV que financia la compra emitiendo bonos en los mercados de capitales. En una titulización sintética la entidad no vende activos sino que transfiere el riesgo de pérdida asociado a alguno de sus activos al VPE/SPV contra el pago de una prima de tal entidad al VPE/SPV. La titulización de negocio global es esencialmente un préstamo garantizado con la totalidad de los activos generados por el negocio de la entidad. Para concederle el préstamo la SPV/VPE utiliza el producto de una emisión de bonos al mercado mientras que la entidad otorga la garantía de todos o la mayoría de sus activos a los tenedores de los bonos. El presente documento se refiere exclusivamente al primer tipo de titulización

17 Vehículo de propósito especial o Special Purpose Vehicle, con personalidad jurídica independiente. En nuestro se caso se denomina Fondo de titulización. En algunos casos, como el español, se adopta el esquema fiduciario de patrimonio sin personalidad jurídica, pero separado del resto de figuras del mecanismo.

${ }^{18}$ Existe una presentación realizada por miembros del Tesoro británico (Stephen Pickford) en un seminario organizado por Overseas Development Institute (ODI) el 13 de Mayo de 2004. Cf. S. PICKFORD (2004). En ella se alude a que los compromisos a largo plazo de los países donantes se titulizarán en los mercados internacionales.
} 
privados o públicos responde a los principios esenciales de una titulización de activos. El hecho de no invocar dicha figura de forma expresa puede explicar algunas de las ambigüedades o inconsistencias técnicas de la propuesta ${ }^{19}$.

El Gráfico 3 interpreta el mecanismo de la IFF asimilándola a los usos del mercado. Con el activo de los compromisos futuros de los países donantes, la IFF como Vehículo especial, emite bonos que son asegurados y vendidos por un Sindicato bancario. Una o más Bolsas garantizarán la liquidez de los bonos. Finalmente, con el producto dinerario de la emisión, el emisor -IFF- dispondrá de los fondos necesarios para adjudicar las ayudas previstas a los países del Sur.

Gráfico 3: El Mecanismo de la IFF, siguiendo las pautas de una titulización

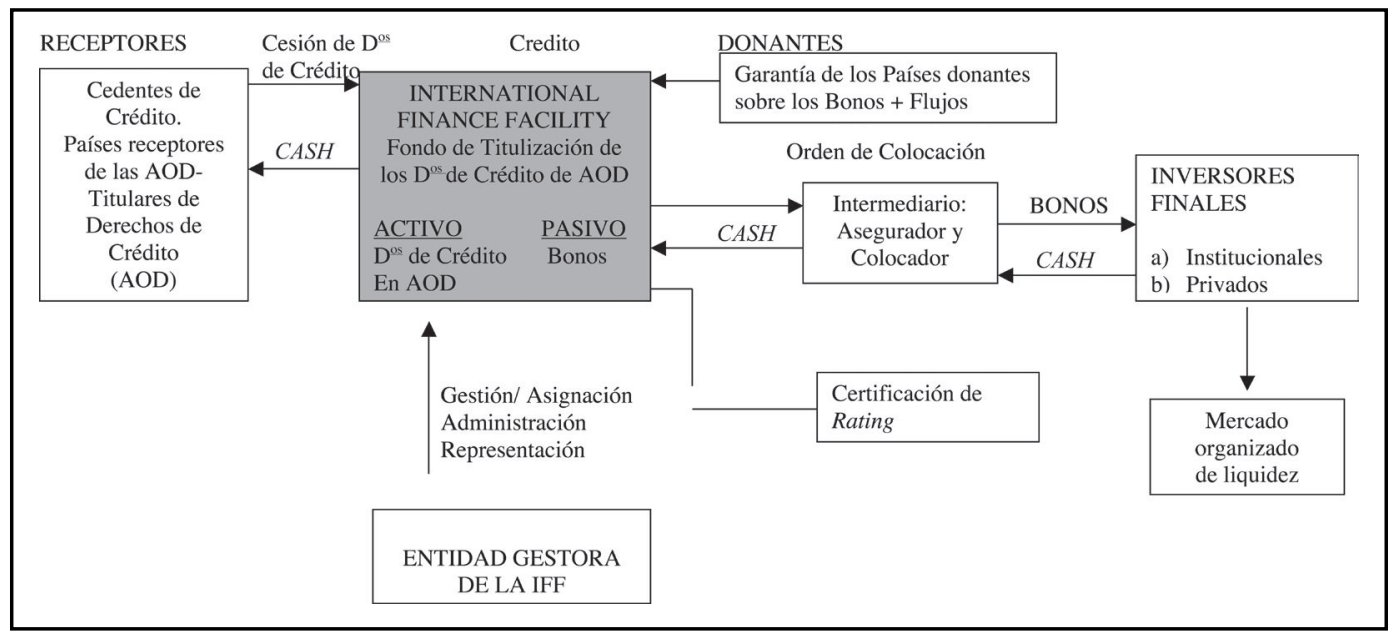

Fuente: Elaboración propia.

19 Dicen sus autores que la IFF representa una iniciativa que monetiza deuda emitida contra compromisos futuros de AOD, de los países donantes a favor de los países pobres. Cabrían, en principio, las siguientes interpretaciones:

a) Una emisión de deuda de los países donantes consignada en los presupuestos corrientes. En este caso se confundiría con cualquier otra forma de AOD (condonación de deuda, implementación del compromiso del 0,7\% AOD/PIB etc), no movilizaría recursos futuros y no responde al espíritu de la IFF.

b) La emisión de deuda se realiza por parte de los propios países donantes con cargo a consignaciones presupuestarias futuras (correspondientes al 2015 y siguientes). Se trataría de una titulización atípica en la que, en cualquier caso, es difícil de explicar el sentido de la aportación de un aval, ya que el riesgo facial es el de un país emisor de rating preferente que subsume en sí mismo al aval innecesario. No responde en consecuencia a los enunciados de la IFF y, muy probablemente, exigiría su consignación en los presupuestos corrientes. A este respecto, repetiríamos la argumentación del párrafo anterior.

c) El titular de la emisión es el propio Vehículo especial, el Fondo de titulización denominado IFF, con el aval de los países donantes a favor de los países mas desfavorecidos. El pasivo del Fondo seguirá siendo el importe de la deuda emitida en circulación y el activo del Fondo lo constituirá el crédito legal y vinculante reconocido bajo forma de aval de los países receptores con procedencia de los países donantes, crédito futuro que se moviliza bajo el principio de la titulización. Esta versión -probable y deseable- aparece tímidamente en el primer documento del Tesoro de Enero 2003 (Cfr. H. M. TReasury (2003)). 
Alguna ambigüedad transmite el enunciado de que "tomar prestado para invertir es un principio bien establecido tanto en el ámbito doméstico como en el del desarrollo. Todos los países donantes toman a préstamo para invertir en prosperidad futura y el mismo Banco Mundial es un tomador tradicional en los mercados de capitales" 20 . Una titulización no es una operación de empréstito. Al tomar a préstamo el prestatario convencerá al prestamista de su capacidad de generación de caja con el producto interno a las fechas de los vencimientos. El crédito se basa en su capacidad de pago a los vencimientos establecidos. La titulización no responde a la toma a préstamo de cantidades "en abstracto" y contra la propia capacidad de generación de caja.

La titulización en general, y la IFF en particular, descuentan en firme (esto es, "venden") con la emisión de bonos un derecho de crédito sustantivado en un compromiso formal -pledge-, y no responde a un recurso al crédito o al empréstito a la manera que lo hacen "todos los países donantes para invertir en prosperidad futura", o al estilo del "mismo Banco Mundial". Por si ello fuera insuficiente, la relación facial de un préstamo / empréstito ordinario es permanente. Por el contrario, al movilizar el derecho de crédito y venderlo al vehículo especial, el cedente -en nuestro caso los países pobres- obtiene liquidez a cambio de los bonos que amparan el derecho de crédito. Al exteriorizar o exportar el derecho de crédito a cambio de caja, el Vehículo especial es el nuevo titular del crédito y desaparece cualquier apelación cerca del cedente originario, renunciándose a lo que en algunos ordenamientos se conoce como la cláusula "salvo buen fin".

Aunque las siglas IFF responden a nuestro entender a la totalidad de un proceso, asumimos el enfoque del DB/IFF para que pueda identificarse, si así se desea, con el propio Fondo de titulización, sin personalidad jurídica -fiduciaria- 0 , en su caso, con personalidad jurídica independiente. Se trata de un Vehículo especial en cuyo activo figuran los derechos de crédito cedidos por los países receptores de AOD y en cuyo pasivo lucen los bonos objetos de comercialización. Como se ha dicho, llegado este momento, la garantía escrita e incondicional de los países donantes reviste una importancia crítica para el buen fin de la operación. Para que esta sea un éxito las empresas de rating deberán otorgar a las emisiones el máximo nivel.

Adicionalmente, la entidad gestora (es el organismo que prepara las emisiones y las administra) parece confundirse con el propio Fondo de titulización. Huyendo de posibles nuevas burocracias y de la acumulación de costes innecesarios, se establece que la IFF no va a ser una nueva agencia de asignación y distribución de fondos y que estos importantes menesteres deberían realizarse a través de cauces de probada solvencia técnica fuesen de naturaleza bilateral o de algunos organismos multilaterales ya existentes como el FMl, el Banco Mundial, etc. Más adelante, sin embargo, el DB/IFF señala que en dicha entidad -se refiere a la IFF- debiera repensarse el tema de la gobernanza dando un mayor protagonismo a los países receptores, extremo al que hay que acordar toda la lógica, ya que son ellos los que titulizan sus derechos de crédito frente a los países donantes. Un esquema de gobernanza ad hoc situaría a la entidad gestora -se confunda o no con el Fondo de titulización- en una posición diferenciada de los organismos bilaterales o multilaterales anteriormente invocados. En consecuencia, en el futuro concepto de IFF, la gobernanza específica y no confundida con organismos existentes y, en su caso, la singularidad de la entidad gestora, deberán ser objeto de una mayor precisión.

${ }^{20} \mathrm{DB} / \mathrm{IFF}$ 3.4. p. 13. 


\section{Viabilidad política ${ }^{21}$}

El 7 de noviembre de 2006 ha tenido lugar una financiación inaugural o experiencia piloto bajo técnica IFF, denominada IFFIm (International Finance Facility for Immunisation) ${ }^{22}$. La emisión fue cerrada en un brevísimo lapso de tiempo con prorrateo por exceso de demanda. Las fuentes básicas de la emisión se concentran en la web de la IFFIm ${ }^{23}$, y en el prospecto o folleto oficial (PR/IFFlm). Se pueden conseguir copias de este último en Citicorp Londres ${ }^{24}$ o en la Bolsa de Luxemburgo ${ }^{25}$.

En cuanto que materialización simbólica de un proyecto de largo alcance, supone un avance político importante, y nos permite contrastar el perfil de partida del instrumento de cara a emisiones futuras.

El objetivo primario de la IFFIm es proveer fondos para programas de inmunización y/o vacunación de GAVI (Global Alliance for Vaccines and Immunisation) en 70 de los países más pobres del mundo ${ }^{26}$. La IFFIm emitirá bonos por un importe total de 4 mil millones de dólares USA entre 2006 y $2015^{27}$. El cuarto Objetivo del Milenio (MDG4) consiste en la reducción en $2 / 3$ de la tasa de mortalidad de niños menores de 5 años para el 2015. Los programas de inmunización de niños menores de 5 años pueden contribuir de forma importante al logro del Objetivo 4. GAVI lleva trabajando desde el 2000 para salvar vidas de niños y proteger la salud de las personas a través del uso generalizado de vacunas en países pobres ${ }^{28}$.

\footnotetext{
${ }^{21}$ En Setiembre de 2005, en la Cumbre de Revisión del Milenio, nuevamente un determinado número de donantes soberanos reafirma su compromiso para alcanzar los ODM, incrementando su AOD e implementando nuevos mecanismos de Financiación. La IFFIm es una de sus consecuencias.
}

22 InTERnAtional FINANCE FACIITY FOR IMMUNISATION (2006). Issue of US. \$1,000,000,000, 5.00per cent. Inaugural Notes due 14 November 2011 under the Global Debt Issuance Programme.

${ }^{23}$ Cfr. International Finance Facility for Immunisation (2006).

${ }^{24}$ Citicorp Trustee Company Limited, Citigroup Centre, Canada Square, London E14 5LB.

${ }^{25} \mathrm{Cfr}$ www.bourse.lu.

26 PR/IFFIm p.6. GAVI fue creada para responder y combatir las tasas decrecientes de inmunización de los países pobres. GAVI es un partenariado público-privado formado por los siguientes miembros permanentes: OMS, UNICEF, Banco Mundial, la Fundación Bill y Melinda Gates y el Fondo GAVI,representantes de gobiernos de naciones ricas y pobres en turno rotatorio y representantes de los campos de la vacunación, la salud y la investigación. Desde 2000, GAVI ha comprometido más de 1,6 mil millones de dólares USA a favor de más de 70 países del sur. PR/IFFIm p. 8.CF. www.gavialliance.org y http://vaccinealliance.org

${ }^{27}$ PR/IFFIm. p.7.

${ }^{28}$ La OMS estima que 27 millones de niños no son vacunados de las enfermedades infantiles más comunes. Como resultado de ello, entre 2 y 3 millones de niños mueren anualmente a causa de enfermedades fácilmente prevenibles. La misma Organización cree que los recursos de la IFFIm pueden conducir a la vacunación de más de 500 millones de personas en los próximos 10 años con el objetivo de prevenir la muerte de 5 millones de niños y 5 millones de adultos. Cfr. www.gavialliance.org . 
La primera emisión realizada ha sido de 1.000 millones de dólares dentro de un programa de 4 mil millones, con fecha de emisión 14 de noviembre 2006 y vencimiento 14 de noviembre 2011 , al tipo de interés de 31 puntos básicos sobre el bono subyacente (5\% anual fijo), precio de emisión 99,916\% (Yield 5,019\%), redimible a la par, al vencimiento, y cotizado en la Bolsa de Luxemburgo. Rating del emisor (IFFIm) y de los bonos: AAA/Aaa/AAA ${ }^{29}$.

El procedimiento de actuación de la IFFIm se recoge en el Gráfico $4^{30}$, y se reconduce fácilmente con el descrito en el Gráfico 3; ilustra sobre el flujo de caja entre IFFIm, donantes (grantors) y otros participantes que, como ha quedado dicho, permite validar el sistema como una titulización. Así lo entienden también el regulador bancario y la Oficina estadística comunitaria ${ }^{31}$.

\section{Gráfico 4: Flujos de la IFFIm}

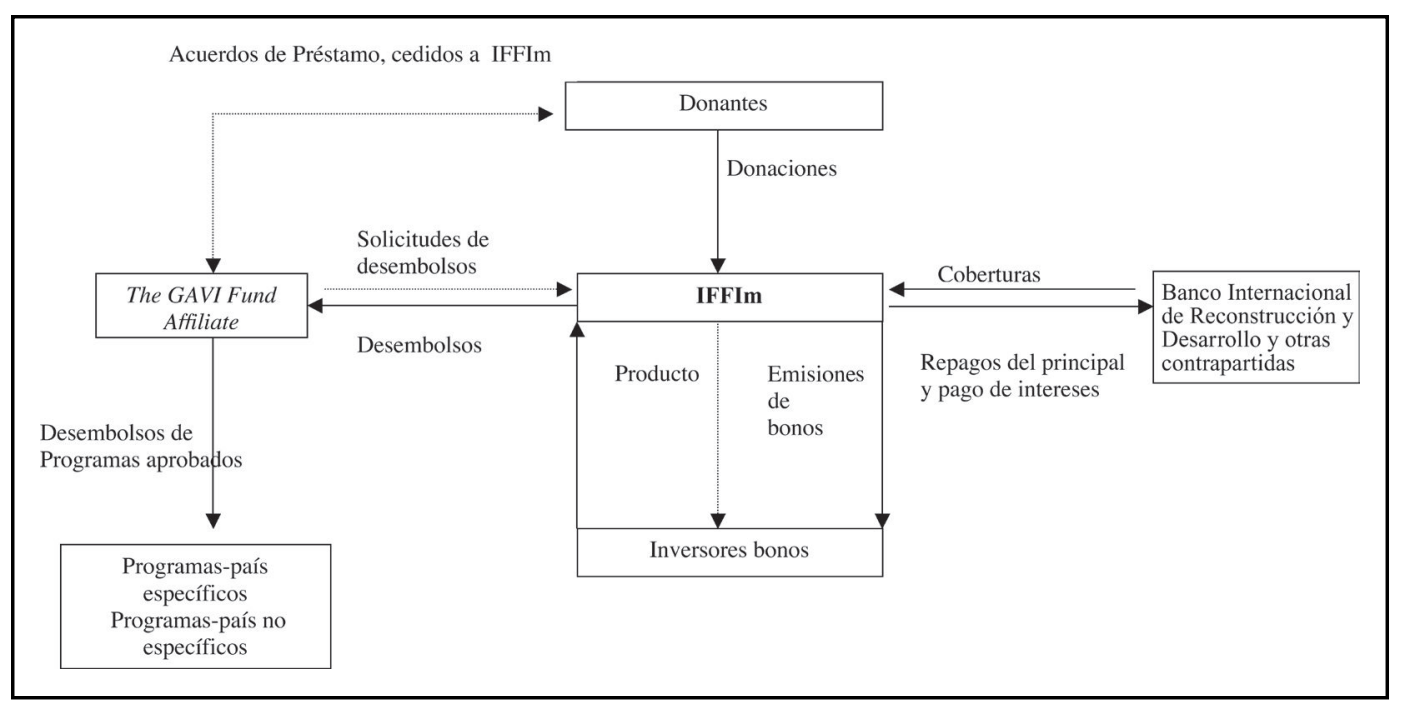

Fuente: RP/IFFIm.

29 Formato Eurobond 144a, Reg S; Sistemas de Clearing:Euroclear, Clearstream y DTC; Codigo ISIN: XS0274548287.

30 PR/IFFIm p. 16.

${ }^{31}$ El 2 de agosto de 2005, Eurostat, en relación a la IFFIm establece: a) que IFFIm debe ser clasificada como "organización internacional" en el epígrafe "resto del mundo", y b) que las donaciones de los gobiernos se clasificarán como pagos corrientes y se registrarán cuando dichos pagos sean exigibles, afectando en ese momento al endeudamiento neto del sector público. Cf. Eurostat (2005). La consecuencia de lo anterior es que los acuerdos de donación no se contabilizarán en el momento de la firma sino en el de las sucesivas entregas efectivas, aliviando así las ratios de deuda de los países donantes. La disposición establece que "no sienta precedente" para futuras IFF. Por otra parte, el 24 de Octubre de 2006, el Comité de Basilea de Supervisión Bancaria anunció que las entidades supervisoras y reguladoras bancarias podrían autorizar la ponderación del $0 \%$ a las posiciones de los bancos en IFFIm (Basel II Framework, Junio 2004) PR/IFFIM Pág 7. 
Junto al emisor (IFFIm) y al receptor directo de los fondos (GAVI Fund Afiliate), describiremos someramente el gestor de tesorería y los países donantes. El Banco Mundial ha sido nombrado tesorero de la IFFlm. Sus obligaciones incluyen, entre otras, las siguientes: valorar la capacidad de financiación de IFFIm para abordar los programas de vacunación / inmunización que le sean presentados por GAVI Fund Afilliate; valorar periódicamente la capacidad de financiación de IFFIm para hacer frente a sus obligaciones en relación con programas previamente aprobados por este, así como de los bonos en circulación; proveer servicios de administración de cuentas; recomendar las políticas de financiación, gestión de riesgo, gestión de inversión y liquidez de IFFIm; una vez aprobadas dichas políticas, ejecutar todas las transacciones financieras contempladas; asesorar a IFFIm sobre todos los aspectos relacionados con la emisión de bonos bajo un determinado programa; como garante de la solvencia y rating del emisor y de las emisiones vigilará el "ratio de maniobra" 32 que no debe sobrepasar en el proyecto piloto inicial el 100\% del valor neto actual del cociente entre el pasivo exigible menos los activos líquidos de la IFFIm dividido por sus activos financieros, esto es los fondos que figuran comprometidos en el Acuerdo de pagos.

Los donantes del programa de lanzamiento y, por tanto, de la emisión piloto son los siguientes países: Francia, Italia, Noruega, España, Suecia y Reino Unido. Todos ellos han firmado un compromiso irrevocable (grant agreemenA) por el que ponen a disposición de IFFIm la suma de 4 mil millones de dólares entre el 31 de Octubre de 2006 y el 15 de Octubre de $2026^{33}$. Brasil y la República Sudafricana han anunciado su intención de comprometer fondos adicionales. Estos países son los adelantados y marcan la pauta inicial para ser secundada globalmente por la comunidad de países en los términos cuantitativos de la propuesta de Gordon Brown.

El acuerdo de pagos, como calendario "garantizado" de flujos futuros de ayuda es el punto clave de la función titulizadora. En base a él, el emisor actualiza flujos de caja que dedica inmediatamente (carga frontal) al alivio de la pobreza. El instrumento está ahí y es operativo. Salvar más vidas, hoy. He ahí el mensaje nuclear ${ }^{34}$.

El Cuadro 1 establece algunas equivalencias entre la propuesta genérica de la IFF de Gordon Brown y la emisión piloto de la IFFIm.

\footnotetext{
32 "IFFIm Gearing Ratio Limit"PR/IFFIm. Pag 92.

${ }^{33}$ Francia $€ 372.800 .000$; Italia $€ 473.450 .000$; Noruega U.S.\$27.000.000; España $€ 189.500 .000$; Suecia SEK 276.150 .000 y Reino Unido 11.380 .000 .000 .
}

\begin{abstract}
${ }^{34}$ Un conjunto de atributos adicionales que figuran en el PR/IFFIm corroboran esta tesis, aun cuando se evite la mención expresa de la titulización. Así: los bonos son obligación exclusiva de la IFFIm (PR/IFFIm, p.26); el recurso contra la IFFIm por el principal y los intereses de los bonos es limitado (PR/IFFIm, p 26); los bonos son obligaciones corporativas exclusivas de IFFIm (PR/IFFIm, p. 26); los activos de la IFFIm son limitados (PR/IFFIm.Pág 26); el IFFIm no corre con responsabilidad alguna del buen fin de los donantes (PR/IFFIm, p. 27); el servicio financiero de los bonos depende de la solvencia de los donantes (PR/IFFIm.p. 27).
\end{abstract}


Cuadro I. Equivalencias entre la Propuesta Genérica de la IFF de Gordon Brown y la emisión Piloto de la IFFIm.

\begin{tabular}{|c|c|c|}
\hline Descripción & IFF (Formato Británico) & IFFIm (GAVI) \\
\hline $\begin{array}{l}\text { Programas y } \\
\text { emisiones }\end{array}$ & $\begin{array}{l}\text { Programa vencimiento } 2030 \\
\text { Emisiones a } 15 \text { años }\end{array}$ & Programa a 10 años (2006-2015). Emisión a 5 años \\
\hline $\begin{array}{l}\text { Importe anual de las } \\
\text { emisiones. }\end{array}$ & $50.000 \mathrm{MM}$ de dólares & $1.000 \mathrm{MM}$ de dólares \\
\hline $\begin{array}{l}\text { Fecha inicio } \\
\text { emisiones }\end{array}$ & 2005 o antes & 2006 \\
\hline $\begin{array}{l}\text { SPV o Vehiculo } \\
\text { especial (al mismo } \\
\text { tiempo "el emisor".) }\end{array}$ & Sin precisar & $\begin{array}{l}\text { "International Finance Facility for Immunisation Company". } \\
\text { Sociedad de Responsabilidad Limitada en Inglaterray Ga- } \\
\text { les y Fundación no lucrativa. Su único titular es GAVI. }\end{array}$ \\
\hline $\begin{array}{l}\text { Rating del emisor y } \\
\text { de la emisión. }\end{array}$ & Máximo/a & Máximo/a: AAA/Aaa/AAA \\
\hline $\begin{array}{l}\text { Cupón o coste de la } \\
\text { emisión }\end{array}$ & $\begin{array}{l}\text { Asimilable a emisiones de riesgo } \\
\text { soberano (Prime) }\end{array}$ & $\begin{array}{l}\text { Asimilado a Emisiones de Riesgo Soberano. Cupón tipo } \\
\text { fijo } 5 \% \text { anual, resultante de } 36 \text { puntos básicos sobre el } \\
\text { subyacente del tesoro americano al mismo plazo ( } 5 \text { años). } \\
\text { Euribor flat a } 5 \text { años en la fecha de la emisión. }\end{array}$ \\
\hline Entidad gestora & $\begin{array}{l}\text { Sin precisar, aprovechando } \\
\text { Organismos multilaterales ya } \\
\text { existentes. }\end{array}$ & IFFIm Treasury Manager. Banco Mundial \\
\hline Avales y donaciones & $\begin{array}{l}\text { Donaciones corrientes y avales } \\
\text { sobre cantidades futuras }\end{array}$ & $\begin{array}{l}\text { Grant Agreement. acuerdo de pago a } 20 \text { años, con una } \\
\text { primera titulizacion piloto a } 5 \text { años. }\end{array}$ \\
\hline Países donantes & Amplio $n^{\circ}$ de países del Norte & UK, F, I, E, S, N. \\
\hline Emisor & IFF & $\begin{array}{l}\text { IFFIm como cesionario de todos los derechos de GAVI. El } \\
\text { producto de las emisiones revierte en primera instancia } \\
\text { en GAVl y luego en los países del Sur. }\end{array}$ \\
\hline Sindicato bancario & $\begin{array}{l}\text { Al uso de los mercados inter- } \\
\text { nacionales }\end{array}$ & Al uso de los mercados internacionales \\
\hline Cotización & Bolsa o Bolsas de primer nivel & Bolsa de Luxemburgo \\
\hline Beneficiarios finales & Países del Sur & $\begin{array}{l}\text { GAVI Fund Afiliate para su asignación a } 70 \text { países del } \\
\text { Sur. }\end{array}$ \\
\hline Objeto del programa & ODM, en general & ODM n 4 \\
\hline $\begin{array}{l}\text { Problemas de } \\
\text { contabilización }\end{array}$ & $\begin{array}{l}\text { Abierta la ponderación Basilea } \\
2 \text { en riesgo IFF y el cómputo } \\
\text { de programas como deuda } \\
\text { corriente. }\end{array}$ & $\begin{array}{l}\text { Cerrados } \\
\text { 1.- UE: inclusión de IFFIm como Banco de Desarrollo } \\
\text { multilateral. } \\
\text { 2.- Basilea 2: ponderación } 0 \% \text { para posiciones en } \\
\text { IFFIm. } \\
\text { 3.- Programas IFF no son deuda corriente. }\end{array}$ \\
\hline Suscripción & Mercado & Detalle de la suscripción \\
\hline Ley & Indeterminada & Inglesa, española, italiana. \\
\hline $\begin{array}{l}\text { Objeto de la } \\
\text { titulización }\end{array}$ & $\begin{array}{l}\text { Avales sobre AOD prevista por } \\
\text { los donantes a partir de } 2015\end{array}$ & $\begin{array}{l}\text { Grant Payments (Compromisos anteriores a 2015, según } \\
\text { calendario anual, con pagos desde } 31 \text { Octubre 2006). }\end{array}$ \\
\hline $\begin{array}{l}\text { Cláusula de } \\
\text { condicionalidad }\end{array}$ & $\begin{array}{l}\text { Enunciada como condición fi- } \\
\text { nanciera de rango prioritario }\end{array}$ & Misma cláusula. \\
\hline $\begin{array}{l}\text { Mecanismo de carga } \\
\text { frontal }\end{array}$ & $\begin{array}{l}\text { No crea nuevos recursos, los } \\
\text { adelanta. }\end{array}$ & $\begin{array}{l}\text { Es dudosa la consignación. Aparentemente se trata de } \\
\text { recursos adicionales. }\end{array}$ \\
\hline $\begin{array}{l}\text { Mecanismos de } \\
\text { vigilancia }\end{array}$ & No se citan. & Gearing ratio. \\
\hline
\end{tabular}




\section{Luces y sombras del proyecto}

\section{I. Luces del proyecto}

El primer mérito de la iniciativa británica reside en el aldabonazo que propina en las puertas de la comunidad internacional de países ricos con el fin de obtener algún tipo de financiación suplementaria que permita seguir acariciando la idea de alcanzar los ODM. Despierta las conciencias y promueve alineamientos contradictorios, de por sí positivamente dialécticos en principio, alargando el compromiso político contraído en Monterrey $2002^{35}$.

En segundo lugar, la IFF distribuiría, como efecto impacto, más fondos en ayuda de los que se hubieran distribuido de otra manera entre 2007 y $2017^{36}$. Los informes de World Development Movement ${ }^{37}$, y Centre for Global Developmen ${ }^{8}$ tratan de cuantificar este efecto. Aunque la fertilidad política se ha reducido al día de hoy a una microemisión, estamos ante recursos adicionales en el corto plazo y quizás también en el plazo integral.

En tercer lugar, la IFF podría resultar en un cambio cualitativo en la efectividad de la ayuda a través del acuerdo de los donantes respecto de los llamados "principios básicos" como los de la ayuda no vinculada y otros ${ }^{39}$. En la actualidad los flujos bilaterales de ayuda se realizan más en función de criterios de política exterior que en base a las necesidades intrínsecas de los países más pobres. La IFF prevé dirigir la asignación de sus fondos hacia los países más pobres, si bien este alto principio como otros más está abierto a la negociación de los países donantes. Muchos países vinculan además la concesión de ayudas a contratos con compañías nacionales. La propuesta IFF prevé desvincular la ayuda de dichos contratos.

Como cuarto aspecto, la IFF provee de la predictibilidad y de la masa crítica de ayuda necesaria para acometer inversiones extensivas, simultáneas y sostenidas entre sectores, abordando las causas antes que los síntomas de la pobreza ${ }^{40}$. En efecto, en el momento actual, uno de los problemas básicos que concurren en los flujos de ayuda es que los receptores carecen de certeza respecto del importe de la ayuda disponible en un determinado horizonte temporal. Esto impide su habilitación para una planificación racional y efectiva. Un sistema de tracto sucesivo con financiación garantizada en cuantía y plazo mejoraría las previsiones de utilización de la ayuda para su uso efectivo durante la vida de la IFF.

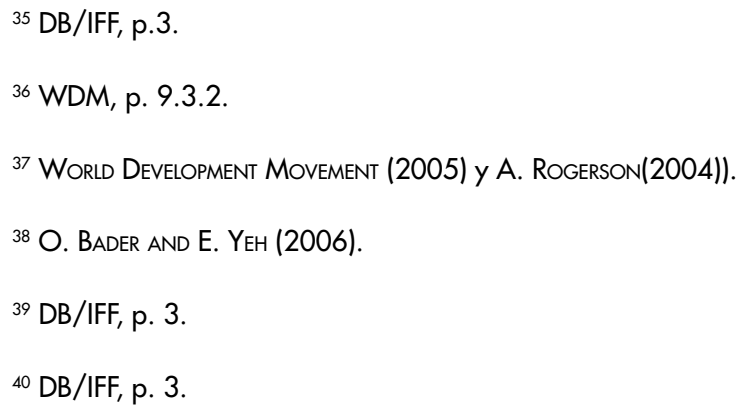


Por lo demás, la IFF es un instrumento de consenso. Ha recibido amplio respaldo de países emergentes, países en desarrollo, instituciones internacionales ${ }^{41}$, comunidades religiosas, ONG y empresas del sector privado. A este respecto la web del Tesoro británico ofrece abundante contribución documental ${ }^{42}$. En abril de 2004 los países africanos miembros del Banco Mundial asumieron en masa el modelo IFF. La Comisión para África lo ha endosado formalmente ${ }^{43}$.

\subsection{Sombras del Proyecto}

Para comenzar, el propio gobierno británico, autor de la propuesta, interpreta que no todos los países en desarrollo son capaces de planificar y utilizar eficazmente ayudas masivas suplementarias y que muchos encontrarán notables cuellos de botella en la dimensión y eficiencia de sus sectores públicos. Debido a ello -se postula- la IFF debe activar el flujo de ayudas de forma gradual hasta alcanzar la cifra objetivo de los 50 mil millones de dólares año. Asimismo, se añade, los países donantes deberán colaborar con los gobiernos de los países receptores para mejorar los sistemas de canalización, distribución y materialización de fondos ${ }^{44}$.

Una objeción impactante, pero a nuestro entender discutible, residiría en la suma total de AOD activada, en comparación con la suma de flujos históricos previstos sin la IFF en un escenario de 30 años $^{45}$. En la medida en que los intereses de la deuda titulizada y las amortizaciones de la misma al vencimiento se produzcan contra presupuestos corrientes proyectados de AOD, la IFF incrementará dicha ayuda inicialmente, pero al término del programa resultará en una pérdida neta. La razón es que la titulización genera unos intereses, con cargo al presupuesto de ayuda corriente de los países donantes, que se destinará al mercado de capitales, a los inversores finales de la deuda titulizada y no a los países receptores ${ }^{46}$. Alineándonos con los análisis realizados por el World Development Movement ${ }^{47}$ y otros, el servicio de la titulización resulta en más dinero a corto plazo, menos dinero a medio plazo con un saldo global negativo financiero para el conjunto de la operación. Pero este argumento, correcto aritméticamente, asume una política de $A O D$ de suma cero que parece difícil compartir en un escenario de 20 años. Los 4 mil millones de dólares del proyecto piloto de inmunización tienen toda la apariencia

\footnotetext{
${ }^{41} \mathrm{DB} / \mathrm{IFF}$, p. 4.

${ }^{42}$ Cfr. H.M. TReAsURY (2004).

${ }^{43}$ COMission for Africa (2005), pp. 333-335.

${ }^{44}$ F. Bourguignon AND M. SUndBerg (2007). Véase también la página del Banco Mundial "Development Effectiveness". Cf. www.worldbank.org

${ }^{45}$ World DeVelopment MOVement (2005).

${ }^{46}$ Así las cosas, la IFF pudiera ser la continuación de lo que tiene en el "alivio de la deuda" su más cercano antecedente. En efecto, el "alivio de la deuda" se reputó en su día como una gran iniciativa que se traduciría en nuevos flujos de caja en dirección a los países pobres. Sin embargo, la realidad ha mostrado que ha procedido en gran medida de los presupuestos ordinarios, con el resultado de una financiación adicional al desarrollo muy exigua.
}

47 World Development Movement (2005), Tabla 1, p. 16. 
de "adicionalidad" en ayuda en un plazo inferior a cinco años, más allá de consignaciones presentes de presupuestos futuros.

Otra incógnita se deriva del principio que se adopte para la gobernanza del Fondo de titulización - la IFF- o en su caso de las futuras gestoras que tengan a bien constituirse. No en vano tendrán que decidir de temas de trascendencia capital como son, entre otros, los llamados "Principios de alto nivel" 48 ya citados. Se supone que no hay que crear instituciones nuevas y que el dinero se desembolsará a través de mecanismos bilaterales y multilaterales ya existentes. Pero ello no excluye que las futuras decisiones se adopten con la participación de los países del Sur. En el caso de la emisión piloto no parece haberse abordado la "negociación" de una nueva gobernanza anunciada en IFF/DB49. Es GAVI quien determina los proyectos calificados dentro del grupo de 70 países elegibles. En todo caso hay que remitirse a la titularidad de GAVI y a la función de Treasury Manager ejercitada por el Banco Mundial para evaluar la autonomía de las decisiones y la participación de los destinatarios finales en las mismas.

Otro punto de inconsistencia se halla en el hecho de que en la IFF "las garantías de los países donantes estarán sujetas a que los países receptores cumplan la condición fundamental de un buen gobierno, cuya trasgresión imposibilitaría al país donante continuar con los pagos anuales comprometidos con la IFF en relación con el tal país receptor" 50 . Esta condición fundamental recibe el nombre de "condición de financiación de primer nivel" indicado, la condición se concreta en el hecho de estar al día en los pagos debidos al FMI ${ }^{52}$.

Si el mercado interpretase que la cláusula habría de afectar a un número importante de países, desalentaría a los inversores incapaces de adquirir un bono con una garantía sujeta a condiciones suspensivas. Sorprende, por tanto, que aun sujeta a dicha cláusula, la emisión piloto haya obtenido el máximo rating de mercado por parte de las tres principales agencias de calificación. En la actualidad, 4 de los 70 países elegibles por GAVI están en situación de impago con el FMI y sujetos a la cláusula de condicionalidad ${ }^{53}$. Este es, sin embargo, un problema importante, ya que si la demanda de bonos fuera escasa, el proyecto se vendría abajo. La experiencia piloto, como hemos dicho, ha sido positiva, pero el comportamiento del mercado en el futuro es una incógnita.

Una sombra adicional para el despegue franco de la IFF, recae en la posibilidad de que el número de países que se adhieran al proyecto sea exiguo y, en su caso, no cuente con el apoyo

${ }^{48}$ High Level Principles: IFF/DB.

${ }^{49}$ IFF/DB 2004, p. 18.4.10.

${ }^{50} \mathrm{IFF} / \mathrm{DB} 2004$.

${ }^{51}$ High Level Financing Condition DB/IFF 2004.

${ }^{52}$ Grant Payment Condition. PR/IFFIm. p. 65.

${ }^{53}$ PR/IFFIm. pp. 7 y 65. Se trata de Liberia, Somalia, Sudán y Zimbabwe. Dado que cada uno de esos países tiene un peso del $1 \%$ en el peso total del Grant Agreement, según se establece en la Pág. 13 del prospecto, los países donantes retirarán un $4 \%$ de la ayuda comprometida a GAVI en tanto dichos países no regularicen su situación. 
de alguna o algunas de las grandes potencias mundiales con su correspondiente efecto tractor. En la actualidad dos escépticos destacados de la IFF son Estados Unidos y Japón y todo apunta a que no secundarán la iniciativa en el corto plazo.

\section{Conclusiones}

El enfoque específico del presente trabajo ha querido ser más técnico que apologético. Desmenuzar analíticamente una propuesta del calado de la del Tesoro británico es sin duda un ejercicio necesario para no alimentar vanas esperanzas y adelantar en su caso carencias y puntos discutibles. Precisamente porque el objeto subyacente, aquel al que va dirigido y orientado el instrumento, consiste en mitigar el lacerante escándalo de la pobreza de los países más desfavorecidos del planeta, el análisis se hace más necesario que nunca antes de acceder a la compulsividad moral de la acción.

Ha sido necesario verificar si la IFF es una propuesta válida, ya que la titulización de unos activos, en este caso derechos de crédito, futuros, es una práctica útil y frecuente en los mercados de capitales para movilizar ingentes sumas de recursos como las reclamadas para el cumplimiento de los ODM. Con la experiencia Piloto (IFFIm) se ha comprobado que los mercados financieros han reaccionado muy favorablemente a la emisión, porque es una construcción tan legítima como inteligente al someterse a los usos y costumbres técnicas de los mercados financieros.

En cuanto que privilegia el plazo medio, hasta 2015, sobre el largo plazo, 2016 a 2032, puede contribuir, de superarse los problemas conceptuales detectados, a la financiación de los ODM. Puesto que el hombre es un ser esencialmente ligado a la dimensión tiempo, un adelanto de fondos futuros que pueda paliar la pobreza hoy -es nuestra tesis- tiene un valor incuestionable, por lo que nos posicionamos entre sus defensores.

La IFF sería, con todo, insuficiente para alcanzar los objetivos pretendidos de alivio de la pobreza en el mundo, si no se abordan simultáneamente otros problemas de índole cualitativa, entre los que hay que destacar las condiciones inapropiadas de política económica que han sido impuestas a los países pobres durante los últimos 25 años. Tal vez lo que la economía del desarrollo necesite es una revisión en profundidad de sus enfoques estructurales tradicionales, para convertirse, a modo de la medicina moderna, en una profesión de enfoque individual dentro de la multiplicidad de causas que en ella convergen. Jeffrey Sachs denomina a dicho enfoque "economía clínica" 54 .

La IFF no debería distraer, en su caso, ni encubrir o demorar y menos sustituir el secular objetivo del $0,7 \%$ del PIB que los países ricos han comprometido en AOD. Recordando que el objetivo fue asumido hace 40 años, si en 2006 todos los países donantes hubieran alcanzado siquiera el $0,45 \%$ del PIB, ello supondría respecto de las cifras efectivas actuales una suma adicional de alrededor de 50 mil millones de dólares al año, importe superior al que espera alcanzarse por

${ }^{54}$ J. D. SACHS (2005b). 
medio de la IFF55. En este déficit de colaboración apoyamos nuestro concepto de titulización de una ilegítima moratoria en los compromisos establecidos de AOD. Si el trasvase o anticipo temporal de fondos que supone la IFF, frenase, demorase o en su peor acepción compensase el ritmo de cumplimiento AOD/PIB hasta la cota establecida del 0,7\%, estaríamos asistiendo, además de la moratoria citada, a una clara y grave omisión de cara al imperativo moral de erradicación o atenuación de la pobreza. La esperanza necesaria queda depositada en un macro-programa IFF que no sólo anticipe sino que también agregue AOD en el tiempo, y ello en las sumas programáticas del enunciado inicial del Gordon Brown, sin otra demora ni interpretación.

\section{Referencias bibliográficas}

Brader, O. AND E. YeH (2006), The Costs and Benefits of Front-loading and Predictability of Immunization. Working Paper 80. Agosto.

http://www.cgdev.org/content/publications/detail/6178?print=1 \&id=6178\&datatype $=5$

Bourguignon, F. ANd SundBerg M. (2007), Aid Effectiveness-Opening the black Box, Washington DC, The World Bank.

CAFOD (2005), Response to the IFF.CF.: www.cafod.org.uk.

CIDSE (2005), New Resources for Development. Position Paper. August 2005.

COMission for Africa (2005), Our Common Interest, pp. 333-335.

EщIO, L. (2005), The Guardian, 7.02.05.

EUROSTAT (2005), Accounting implications of the International Finance Facility for Immunisation initiative. EUROSTAT news release. 2 de Agosto. http://europa.eu.int/comm/eurostat

Foster, M. ANd Keith, A. (2003), The Case for increased Aid.Final Report to the Department for International Development.Essex.Mick Foster Economics Ltd.

Global Poucy Forum (2003), Tobin Tax Network Position Paper on the International Finance Facility. The Tobin Tax Network. Fall.

http://www.globalpolicy.org/socecon/develop/oda/2003/09iff.htm

H. M. TreAsuRY (2003), International Finance Facility. Cf. www.hm-trasury.gov.uk/media/790/14/ ACF6FB.pdf

H. M. TREASURY (2004), International Finance Facility (2004).Cf. www.hm-treasury.gov.uk/documents/international issues/international development/development iff

${ }^{55}$ OECD (2007). 
International Finance Corporation (2005), Securitization in Russia: Ways to expand Markets and reduce Borrowing Costs. World Bank Group. Cf.: www.ifc.org

International Finance Facility for Immunisation (2006), (Web) www.iffim.com

MaVRotas, G. (2003), The International Finance Facility. Discussion Paper No.2003/79.United Nations University. WIDER. December.

Moss, TODD J. (2004), The Iffy Direction of the IFF. Center for Global Development. Cf.www. cgdev.org.

MOss, TODD J. (2005), Ten Myths of the IFF. Center for Global Development. Cf. www.cgdev.org.

NACIONES UNIDAS (2000), Resolución adoptada por la Asamblea General n55/2. Declaración del Milenio. A/RES/55/2.

NAYYAR, D. ED. (2002), Governing globalization. Issues and Institutions. UNU/WIDER Studies in development economics. Oxford University Press.

OECD (2007), Development aid form OECD Countries fell 5,1\% in 2006. Cf. www.oecd.org

Ouví́, I. y F. SteinBerg (2007), Un Balance de la ayuda al desarrollo 2006, Real Instituto Elcano. Ari 56/2007.

OverseAs DeVelopment Institute (ODI) (2005), The Pilot IFF gets to go-ahead.Agosto 2005. http:// www.odi.org.uk/

OIT (2004), Por una globalización justa. Crear oportunidades para todos, Ginebra, Comisión mundial sobre la dimensión social de la globalización, OIT.

PICKFORD. S. (2004), Seminario organizado por ODI el 13 de Mayo de 2004. Cf. www.odi.org. $\underline{u k} /$ speeches/IFF

Rogerson, A. (2004), The IFF: Issues and Options. Overseas Development Institute (ODI). www. odi.org.uk/opinions15.

SACHS, J. D. (2005a), Investing in Development. A practical Plan to achieve the Millenium Development Goals. Millenium Project. NewYork. Cf. www.unmilleniumproject.org

SACHS, J. D. (2005b), "The end of poverty". Time, March 14,2005.

SORBARA, M. (2005), International Finance Façade. Embassy. Cf. www.embassymag.ca

The Global Fund (2005), Innovative Financing for Global Health: The Internacional Finance Facility (IFF). Ginebra, Julio.

The Technical Group on Innovative Finance Mechanisms (Report of) (2004), Action against Hunger and Poverty. Cf.www.mre.gov.br

Tobin TAx Network (2003), Tobin Tax Network Position Paper on the IFF. Cf. www.globalpolicy.org. 
WAHL, P. (2006), Results of the Conference "Innovative Instruments for Financing Development". WEED.

World Development Movement (2005), The International Finance Facility, Boon or Burden for the Poor? Febrer. Cf. www.wdm.org.uk/resources/briefings/general/iff.pdf

WORLD ECONOMIC FORUM (2005), Global Governance Initiative. Cf.www.weforum.org 